Check for updates

Cite this: RSC Adv., 2019, 9, 26315

Received 15th June 2019

Accepted 11th August 2019

DOI: $10.1039 / c 9 r a 04494 a$

rsc.li/rsc-advances

\title{
Highly selective and sensitive detection of amaranth by using carbon dots-based nanosensor $\uparrow$
}

\begin{abstract}
Lizhen Liu, ${ }^{a}$ Zhi Mi, DD *a Haihong Li, ${ }^{\text {b }}$ Caiqing $\mathrm{Li}^{\text {a }}{ }^{\text {Q }}$ in $\mathrm{Hu}^{\mathrm{c}}$ and Feng Feng (D)*a
In this work, a novel fluorescence nanosensor for selective and sensitive determination of amaranth was constructed using carbon dots (C-dots). Water soluble C-dots with strong fluorescence were obtained by a simple microwave-assisted method using urea and glycine as raw materials. It was found that amaranth can efficiently and sensitively quench the C-dots fluorescence by the inner filter effect (IFE) and non-radiative energy transfer (NRET) mechanisms. The fluorescence quenching efficiency $\left(F_{0} / F\right)$ was strongly correlated with the concentration of amaranth in the $0.2-30 \mu \mathrm{M}$ range. The detection limit (LOD) is $0.021 \mu \mathrm{M}$. There was no significant change in the fluorescence intensity of C-dots when other potentially interfering substances were present in the system. Our C-dots-based nanosensor was successfully utilized for the analysis of amaranth in drinks and showed rapid, sensitive and accurate responses. It indicates that the novel $\mathrm{C}$-dots-based nanosensor has great potential in amaranth detection for real-life applications.
\end{abstract}

\section{Introduction}

Coloration is important for consumer perception and acceptance, because it often correlates with the freshness or acceptability of the food. Food dyes can be either natural or synthetic dyes. Natural dyes are usually extracted from natural sources and show some disadvantages in their properties such as low tinctorial strength, instability toward light, $\mathrm{pH}$, temperature and redox agents, high cost and easy discoloration during processing or storage. Compared with natural dyes, synthetic ones offer colour uniformity, good stability, low cost and strong dyeing power, therefore, they are widely used in the food industry. However, many synthetic dyes pose potential risks to human health and their use is strictly regulated by laws and regulations all over the world.

Amaranth (Fig. S1†), a typical synthetic aromatic azo dye showing fascinating red color, is often used as an additive in foods and soft drinks. However, some studies showed negative effects such as cytotoxicity, cytostatic and genotoxicity of amaranth on human health., ${ }^{1,2}$ Based on Food and Agriculture Organization (FAO) and World Health Organization (WHO) guidance, the acceptable daily amaranth intake should be within $0-0.5 \mathrm{mg} \mathrm{kg}{ }^{-1}{ }^{3}$ Thus, the amount of amaranth in food

${ }^{a}$ Shanxi Datong University, Datong, 037009, PR China.E-mail: mizhi775@126.com; feng-feng64@263.net; Fax: +86-352-6100028; Tel: +86-352-7157968

${ }^{b}$ School of Chemistry and Materials Science, Shanxi Normal University, Linfen 041004, PR China

${ }^{c}$ College of Food Science and Engineering, Yangzhou University, Yangzhou, Jiangsu, 225001, PR China

$\dagger$ Electronic supplementary information (ESI) available. See DOI: 10.1039/c9ra04494a must be strictly controlled and it is of high significance to develop an accurate, sensitive, simple, rapid and economic method for amaranth detection to safeguard human health and food safety. Currently, methods for amaranth determination include high performance liquid chromatography-diode array detector (HPLC-DAD), ${ }^{4,5}$ high performance liquid chromatography-ultra-violet detection (HPLC-UV), ${ }^{6}$ liquid chromatography-mass spectrometry (LC-MS), ${ }^{7}$ electrochemistry, ${ }^{8-10}$ capillary electrophoresis $(\mathrm{CE}),{ }^{11}$ thin layer chromatography (TLC) ${ }^{12}$ and enzyme-linked immunosorbent assay (ELISA $)^{13}$ methods. Although these methods have been effectively used for amaranth detection, they still have some shortcomings such as materials and time consumption, complex operation and expensive instruments. ${ }^{14}$ Compared with other analytical methods, fluorescence method is a preferable method for trace analysis because of its low cost, simple operation, rapid and high sensitivity. ${ }^{15}$

Carbon dots (C-dots) represent a new member family of carbon nanomaterials with former family members of fullerenes, nano-diamonds, graphene sheets and carbon nanotubes. ${ }^{16,17}$ It was first discovered in 2004 during separating and purifying sing-walled carbon nanotubes. ${ }^{18}$ The C-dots are typically almost spherical with sizes less than $10 \mathrm{~nm}$. The C-dots cores generally consist of amorphous carbon or $\mathrm{sp}^{2}$ hybridized carbons. ${ }^{19}$ Since C-dots discovery, various methods have been established to synthesize them, including laser ablation, ${ }^{20}$ chemical and electrochemical oxidation, ${ }^{21,22}$ carbonizing organic molecules, ${ }^{23}$ hydrothermal strategies ${ }^{24}$ and microwave $^{25,26}$ methods. C-dots, as emerging light-emitting nanomaterials, have drawn great attention because of their prominent characteristics such as facile synthesis, easy 
functionalization, favorable photoluminescence, good water solubility, high chemical and photo stability, excellent biocompatibility and low cytotoxicity. ${ }^{27-29}$ These outstanding properties make C-dots a promising material and can be used in the fields of bioimaging, ${ }^{30-32}$ energy conversion and storage, ${ }^{33}$ biomedicine $^{34}$ and photocatalysis. ${ }^{35}$ In addition, C-dots are also widely used to detect various analytes based on changes in fluorescence intensity. Sooksin's group prepared N-doped Cdots and used them as fluorescence nanosensor for $\mathrm{Al}^{3+}$ detection. ${ }^{36}$ Zhang's group synthesized C-dots doped with $\mathrm{N}$ and applied them as nanosensor for $\mathrm{Cr}(\mathrm{vI})$ and ascorbic acid detection. ${ }^{37}$ Zan's group synthesized C-dots simultaneously doped with $\mathrm{P}$ and $\mathrm{N}$ and used them as an effective fluorescent nanosensor for nitrite ions detection. ${ }^{38}$ Dang's group produced Cdots doped with both $\mathrm{N}$ and $\mathrm{S}$ and used them for the detection of $\mathrm{Ag}^{+}{ }^{39}$ Zeng's group produced C-dots with polyethylenimine functionalized for selective detection of 6-thioguanine. ${ }^{\mathbf{4 0}}$ However, as far as we aware, research on the application of C-dots as a fluorescent nanosensor for selective and sensitive detection of amaranth was not published in the literature.

In this work, we first reported the application of C-dots as a fluorescent nanosensor for the detection of amaranth. The Cdots were synthesized using urea and glycine as raw materials. As-synthesized C-dots exhibit excellent solubility in water and show strong fluorescence, which can be efficiently quenched by amaranth. Using these properties of C-dots, we developed a selective and sensitive nanosensor based on fluorescence quenching to detect amaranth. This C-dots-based nanosensor was successfully implemented for amaranth analysis in drinks. The proposed fluorescence method not only exhibited excellent sensitivity and selectivity but also demonstrated its feasibility for practical applications.

\section{Experimental}

\section{Materials}

Amaranth (95\%) was bought from Aladdin Chemistry Limited Company (Shanghai, China). Urea was from Tianjin Jinbei Fine Chemical Limited Company (Tianjin, China). Quinine sulfate was obtained from Sinopharm Chemical Reagent Limited Company (Shanghai, China). Dibasic sodium phosphates $\left(\mathrm{Na}_{2} \mathrm{HPO}_{4}\right)$, sodium hydroxide $(\mathrm{NaOH})$, hydrochloric acid $(\mathrm{HCl})$, sodium dihydrogen phosphate $\left(\mathrm{NaH}_{2} \mathrm{PO}_{4}\right)$ and potassium bromide $(\mathrm{KBr})$ were acquired from Tianjin Zhiyuan Chemical Reagent Limited Company (Tianjin, China). Starch, $\mathrm{KCl}, \mathrm{CaCl}_{2}$, $\mathrm{ZnCl}_{2}, \mathrm{FeCl}_{3}$ and $\mathrm{NaCl}$ were bought from Jiangsu Qiangsheng Functional Chemistry Limited Company (Changshu, China). Glycine, phenylalanine, vitamin $\mathrm{C}$, vitamin $\mathrm{B}_{1}$, tyrosine, threonine, alanine and glutamic acid were purchased from Tianjin Damo Chemical Reagent Factory (Tianjin, China). Glucose and malt sugar were purchased from Tianjin Beichen Fangzheng Chemical Reagent Factory (Tianjin, China). All reagents were analytically pure and used without further purification. Deionized water (resistivity of $18.2 \mathrm{M} \Omega \mathrm{cm}^{-1}$ ) was used in all experiments. Phosphate buffer saline (PBS) solutions with different $\mathrm{pH}$ values of 2-12 were obtained by adding different amounts of
$\mathrm{NaOH}$ or $\mathrm{HCl}(1 \mathrm{M})$ to $0.01 \mathrm{M}$ mixture solution of $\mathrm{Na}_{2} \mathrm{HPO}_{4}$ and $\mathrm{NaH}_{2} \mathrm{PO}_{4} .2 \mathrm{mM}$ amaranth standard solution was prepared by using deionized water as solvent and keep in a refrigerator at $4{ }^{\circ} \mathrm{C}$ for further use.

\section{Synthesis of C-dots}

The C-dots were produced by microwave irradiation of a solution containing urea and glycine. To prepare this solution, $2.0 \mathrm{~g}$ of urea was mixed with $2.0 \mathrm{~g}$ of glycine in $40 \mathrm{~mL}$ of deionized water. The mixed solution was irradiated in a microwave reactor for $3 \mathrm{~min}$ with microwave radiation at $800 \mathrm{~W}$. The resulting brown products were then mixed with $60 \mathrm{~mL}$ of deionized water and dialyzed using dialysis tubing (MWCO, 500-1000 Da) against deionized water for $12 \mathrm{~h}$, after which the C-dots solution was freeze dried.

\section{Characterization}

Transmission electron microscopy (TEM) was performed by a FEI Tecnai F-20 TEM (Hillsboro, USA) instrument at an accelerating voltage of $200 \mathrm{kV}$. TEM samples were prepared by dropping the C-dots aqueous solution onto carbon-coated copper grid which was left to dry before analysis. Fourier transform infrared (FTIR) spectra were recorded using Bruker Tensor 27 FTIR spectrometer (Bruker, Germany) at a resolution of $4 \mathrm{~cm}^{-1}$ in the range of $400-400 \mathrm{~cm}^{-1}$. The C-dots/KBr disk was prepared by mixing few milligrams of C-dots with about $100 \mathrm{mg}$ of $\mathrm{KBr}$ powder, grinding to approximately $2 \mu \mathrm{m}$ in a mortar and subjecting to $29.7 \mathrm{MPa}$ pressure by a pressing machine. X-ray photoelectron spectroscopy (XPS) was performed by using Krato XPS instrument (Krato, UK) with AIK $\alpha$ radiation operating at $1486.6 \mathrm{eV}$. UV-vis absorption spectra were recorded on TU-1800 spectrometer (Beijing, China) in $1 \mathrm{~cm}$ quartz cell and the spectra were collected from 200 to $700 \mathrm{~nm}$. Fluorescence spectra were obtained using F-2500 spectrometer (Hitachi, Japan) equipped with a xenon lamp as the excitation light source. Time-resolved fluorescence decay spectra were performed on an Edinburgh FLS 920 spectrometer (Edinburgh, UK) with the excitation wavelength at $320 \mathrm{~nm}$.

\section{Sensing of amaranth}

For analysis of amaranth, $1800 \mu \mathrm{L}$ PBS solution $(0.01 \mathrm{M}, \mathrm{pH}=7)$ was mixed with $200 \mu \mathrm{L}$ of C-dots solution $\left(1 \mathrm{mg} \mathrm{mL}^{-1}\right)$ and then $30 \mu \mathrm{L}$ of amaranth or sample solution at different concentration (0-2 $\mathrm{mM}$ ) was added (final concentration of the amaranth is $0-$ $30 \mu \mathrm{M})$. The mixed solution was hand-shaken and incubated for $5 \mathrm{~min}$ at ambient environment. $10 \mathrm{~nm}$ was set as the emission and excitation slit width. Fluorescence intensity was obtained at $320 \mathrm{~nm}$ excitation wavelength. Quenching efficiency was calculated based on the relative fluorescence intensity $\left(F_{0} / F\right)$, where $F_{0}$ and $F$ are C-dots fluorescence intensity without and with amaranth presence in the solution, respectively. Other substances such as sugars (glucose, starch and malt sugar), vitamins (vitamin $\mathrm{C}$ and vitamin $\mathrm{B}_{1}$ ), amino acids (glycine, phenylalanine, tyrosine, threonine, alanine and glutamic acid) and salts (KCl, $\mathrm{CaCl}_{2}, \mathrm{ZnCl}_{2}, \mathrm{FeCl}_{3}$ and $\mathrm{NaCl}$ ) were measured under the same conditions for selectivity test. 


\section{Results and discussion}

\section{Characterization of C-dots}

To study the optical characteristics of the C-dots, the UV-vis absorption and fluorescence spectra were characterized. UVvis absorption spectra of C-dots (Fig. 1A) showed a peak appear at $320 \mathrm{~nm}$ because of $\mathrm{n} \rightarrow \pi^{*}$ transition of $\mathrm{C}=\mathrm{N}$ and $\mathrm{C}=$ $\mathrm{O},{ }^{41-43}$ which suggesting nitrogen and oxygen-containing functional groups on the surface of the C-dots. C-dots solution is light yellow color (inset of Fig. 1A). It changed to bright blue fluorescence after exposure to UV light. The maximum emission and excitation wavelengths were observed at 380 and $320 \mathrm{~nm}$, respectively. C-dots fluorescence emission spectra depended on excitation wavelengths (Fig. 1B). When excitation wavelength changed from $300 \mathrm{~nm}$ to $430 \mathrm{~nm}$, the C-dots emission spectra red-shifted from $375 \mathrm{~nm}$ to $475 \mathrm{~nm}$ because of presence of various functional groups on C-dots surface and various sizes of C-dots. $^{44}$ C-dots quantum yield $\left(\Phi_{\mathrm{S}}\right)$ was $13 \%$, which was determined using quinine sulfate as a reference (Fig. $\mathrm{S} 2 \dagger$ ).

TEM was applied to characterize the particle size and morphology of the C-dots (Fig. 2). TEM image shows the C-dots have good dispersion and are nearly spherical. The C-dots particle sizes were distributed in a wide range of 1.3-5.6 nm. The average particle size was $3.3 \mathrm{~nm}$, which was calculated by averaging particle sizes of 100 random particles.

C-dots surface functional groups were determined using FTIR (Fig. S3 $\dagger$ ). A broad absorption band between 3000 and $3500 \mathrm{~cm}^{-1}$ is attributed to $\mathrm{O}-\mathrm{H}$ and $\mathrm{N}-\mathrm{H}$ stretching vibrations. ${ }^{45}$ The absorption bands at 2845 and $2927 \mathrm{~cm}^{-1}$ are ascribed to stretching vibration of $\mathrm{C}-\mathrm{H}$. Absorption bands at 1459, 1605 and $1721 \mathrm{~cm}^{-1}$ correspond to the $\mathrm{CH}_{2}, \mathrm{C}=\mathrm{N}$ and $\mathrm{C}=\mathrm{O}$ stretching vibrations, respectively. Peaks associated with stretching vibrations of $\mathrm{C}-\mathrm{N}$ and $\mathrm{CO}-\mathrm{NH}$ appear at 1155 and $1395 \mathrm{~cm}^{-1}$, respectively. ${ }^{46,47}$ Band at $1080 \mathrm{~cm}^{-1}$ is assigned to the $\mathrm{C}-\mathrm{O}$ bond. ${ }^{48}$ Furthermore, the XPS analysis was also performed to further investigate the detailed compositional information of the C-dots (Fig. 3). Full XPS spectrum (Fig. 3A) shows three main peaks at $285.8,531.5$ and $399.7 \mathrm{eV}$, which corresponded to $\mathrm{C} 1 \mathrm{~s}$, $\mathrm{O} 1 \mathrm{~s}$ and $\mathrm{N} 1 \mathrm{~s}$, respectively, confirming the Cdots mainly contained $\mathrm{C}, \mathrm{O}$ and $\mathrm{N}$. In detail, the high-resolution C 1s spectrum (Fig. 3B) contained peaks at 288.3, 285.9 and
(A)

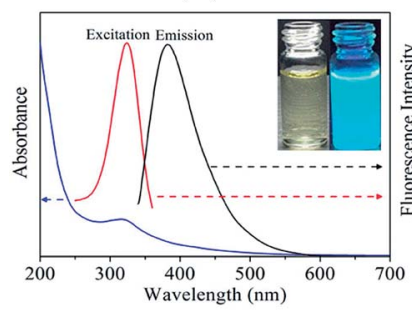

(B)

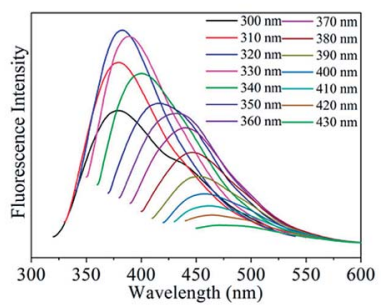

Fig. 1 (A) UV-vis absorption (blue line), excitation (red line) and emission (black line) spectra of the $C$-dots. Inset: photograph image of the C-dots solution under daylight (left) and UV light (right). (B) Fluorescence emission spectra of the $\mathrm{C}$-dots at different excitation wavelengths $(300-430 \mathrm{~nm})$.
(A)

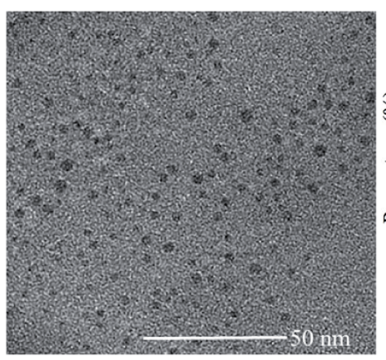

(B)

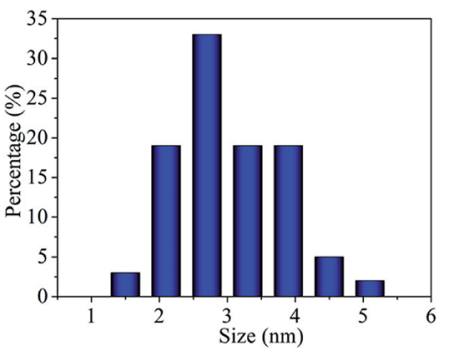

Fig. 2 (A) TEM image and (B) particle size distribution of the C-dots.

$284.5 \mathrm{eV}$, which correspond to $\mathrm{C}=\mathrm{O}, \mathrm{C}-\mathrm{N}$ and $\mathrm{C}=\mathrm{C}$ bonds, respectively. ${ }^{49}$ High-resolution $\mathrm{N}$ 1s spectrum (Fig. 3C) demonstrated peaks corresponding to $\mathrm{N}-\mathrm{H}$ at $402.2 \mathrm{eV}$ and $\mathrm{C}-\mathrm{N}$ group at $399.9 \mathrm{eV}^{\mathbf{5 0}}$ High-resolution $\mathrm{O}$ 1s spectrum (Fig. 3D) confirmed presence of $\mathrm{C}-\mathrm{O}$ and $\mathrm{C}=\mathrm{O}$ groups with corresponding peaks at 531.7 and $531.3 \mathrm{eV}$. Both the FTIR and XPS results agreed on existence of amide, amine, carboxyl and hydroxyl groups on the surface of the C-dots, which ensure excellent water solubility and strong fluorescence of C-dots.

\section{Parameter optimization for amaranth sensing}

To obtain an effective and very sensitive fluorescent nanosensor based on C-dots for amaranth sensing, we optimized factors including dosage of C-dots, $\mathrm{pH}$ of buffer solution and incubation time. $10 \mu \mathrm{M}$ amaranth was used in the whole optimization experiments and the quenching efficiency $\left(F_{0} / F\right)$ was used as the response of each test.

Fig. $\mathrm{S} 4 \mathrm{~A} \uparrow$ shows the effect of $\mathrm{pH}$ on the $F_{0} / F$ in the $2-12 \mathrm{pH}$ range. As the $\mathrm{pH}$ increased from 2 to 7 , the $F_{0} / F$ initially increased and then showed a decrease trend when $\mathrm{pH}$ was higher than 7 . The highest $F_{0} / F$ value was achieved at $\mathrm{pH} 7$. This is due to the reaction of the $-\mathrm{OH}$ of amaranth, which directly
(A)

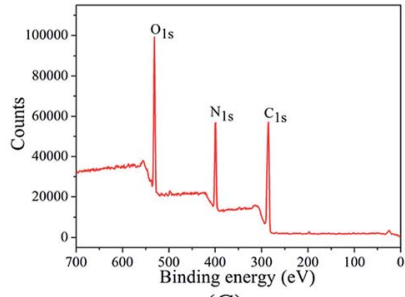

(C)

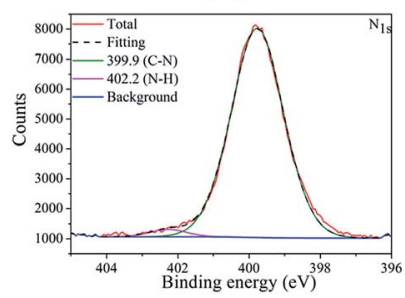

(B)

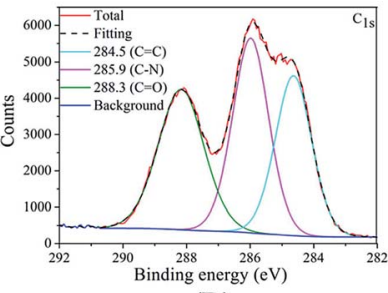

(D)

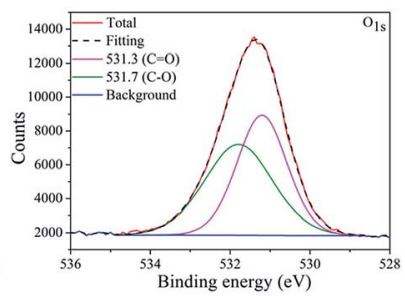

Fig. 3 (A) Full scan XPS spectrum, (B) C 1s spectrum, (C) N 1s spectrum, and (D) $\bigcirc$ 1s spectrum of the $C$-dots. 
influence the interaction between amaranth and C-dots. ${ }^{51}$ Therefore, this value was selected as the optimal one for further sensing experiments.

Fig. $\mathrm{S} 4 \mathrm{~B} \uparrow$ shows the effect of the C-dots dosage on the $F_{0} / F$ in the range of $140-280 \mu \mathrm{L}$. We found that $F_{0} / F$ increased as the Cdots dosage increased from 140-200 $\mu \mathrm{L}$ and then gradually decreased when the C-dots dosage beyond $200 \mu \mathrm{L}$. Thus, we chose $200 \mu \mathrm{L}$ as the optimum one for further sensing experiments.

Effect of the incubation time between C-dots and amaranth on $F_{0} / F$ value is depicted in Fig. S4C. $\dagger$ The $F_{0} / F$ value reached a maximum when incubation time was $1 \mathrm{~min}$. There was no significant change in $F_{0} / F$ after incubation for $1 \mathrm{~min}$, indicating that the C-dots based nanosensor is fast for the detection of amaranth. In order to ensure the stability and the reproducibility of the experimental results, 5 min was chosen conservatively as the optimized incubation time. In conclusion, the optimum conditions for the detection of amaranth were $\mathrm{pH} 7$, $200 \mu \mathrm{L}$ of C-dots solution and $5 \mathrm{~min}$ incubation time.

\section{Amaranth detection}

C-dots fluorescence response to amaranth was analyzed under the optimal conditions discussed above and is displayed in Fig. 4A. As amaranth concentration increased, C-dots fluorescence intensity gradually decreased. It indicated that C-dots fluorescence quenching strongly correlated with amaranth concentration. As displayed by Fig. 4B, C-dots fluorescence quenching positively correlated with amaranth concentration in the $0.2-30 \mu \mathrm{M}$ range. The relationship was linearly fitted $\left(R^{2}=\right.$ $0.9989)$ using the following equation: $F_{0} / F=0.292[C]+1$. The limit of detection (LOD) and the limit of quantity (LOQ) of the proposed C-dots based nanosensor for amaranth detection was measured to be $0.021 \mu \mathrm{M}(\mathrm{S} / \mathrm{N}=3)$ and $0.07 \mu \mathrm{M}(\mathrm{S} / \mathrm{N}=10)$, respectively.

For accuracy and precision evaluation, we performed five consecutive analyses of amaranth content at concentrations equal to 1,15 and $30 \mu \mathrm{M}$. As shown by Table S1, $\uparrow$ the obtained recoveries were $103 \%, 102.7 \%$ and $98.7 \%$ with the corresponding relative standard deviation (RSD) equal to $2.5 \%, 1.2 \%$ and $1.9 \%$, respectively. Thus, our developed novel nanosensor shows excellent precision and accuracy in amaranth detection. Comparison of our sensor performance with other analytical
(A)

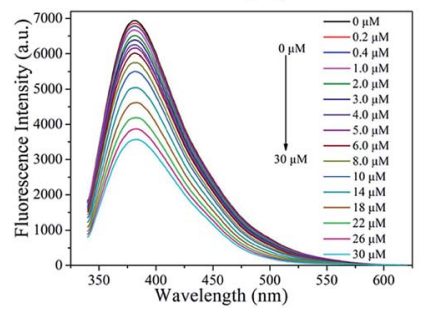

(B)

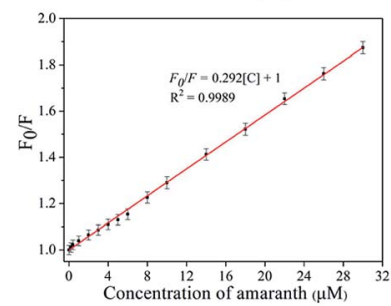

Fig. 4 (A) Fluorescence emission spectra of $C$-dots with addition of different concentrations of amaranth. (B) The plot of $F_{0} / F$ against amaranth concentration in the range of $0.2-30 \mu \mathrm{M}$. The error bars represent the standard deviation of three measurements. methods of amaranth detection is listed in Table S2. $\uparrow^{5,7,8,10-13,52}$ Our proposed method achieves a lower LOD than other reported methods even though it is not as good as ELISA and HPLC-MS detection methods., ${ }^{73}$ However, it is noteworthy that most other reported analytical methods require long analysis time, costly equipment and complex operations while our proposed method is of rapid response, good accuracy and precision, simple operation and low cost, all of which are beneficial to routine amaranth detection in real samples.

\section{Quenching mechanism analysis}

To understand mechanism of C-dots fluorescence quenching by amaranth, we used UV absorption spectra of amaranth and the emission and excitation spectra of C-dots. Absorption spectrum of amaranth overlaps with the emission and excitation spectra of C-dots (Fig. S5A $\dagger$ ). This indicated that C-dots fluorescence quenching by amaranth might be attributed to inner filter effect (IFE) or fluorescence resonance energy transfer (FRET).$^{53}$ For deeper understanding of this quenching mechanism, the timeresolved fluorescence decay spectra of C-dots were measured in the presence and absence of amaranth (Fig. S5B $\dagger$ ). The fluorescence lifetime of C-dots did not change with or without amaranth, which points at IFE-based quenching mechanism. ${ }^{54}$ Meanwhile, the UV absorption spectra of C-dots under different amaranth concentration were recorded (Fig. S5C $\dagger$ ). The UV absorption of C-dots at $523 \mathrm{~nm}$ gradually increased as amaranth concentration increased. We obtained a good linear correlation between UV absorption intensity and the amaranth concentration, which further confirmed the occurrence of IFE. ${ }^{55}$ In addition, the structure of amaranth contains hydroxyl groups, and the surface of C-dots contains a large number of hydroxyl and carboxyl groups as determined by IR and XPS, the hydroxyl groups of amaranth bind to the hydroxyl and carboxyl groups of C-dots through hydrogen bonding, allowing an effective nonradiative energy transfer (NRET) from the C-dots to amaranth, resulting in quenching of C-dots. ${ }^{56}$ So the mechanism of C-dots

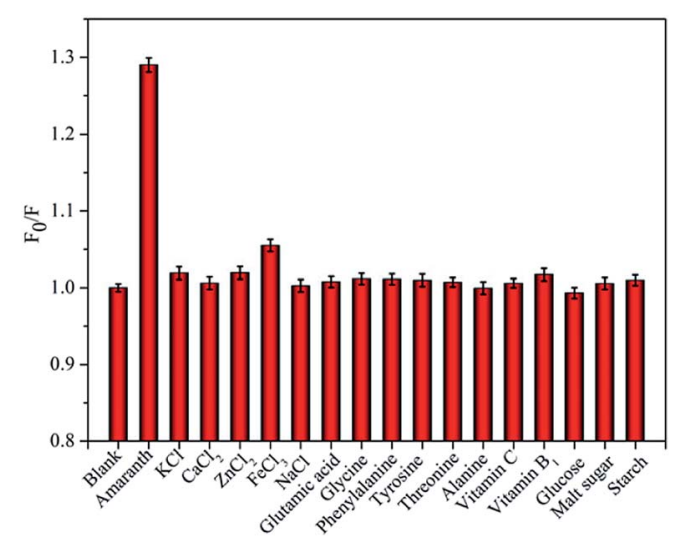

Fig. 5 Fluorescence response of $\mathrm{C}$-dots in the presence of amaranth $(5 \mu \mathrm{M})$, salts $(100 \mu \mathrm{M})$, amino acids $(300 \mu \mathrm{M})$, vitamins $(300 \mu \mathrm{M})$ and sugars $(300 \mu \mathrm{M})$. The error bars represent the standard deviation of three measurements. 
Table 1 Analytical results of amaranth in grape juice drinks $(n=3)$

\begin{tabular}{|c|c|c|c|c|c|}
\hline Sample & Original found $(\mu \mathrm{M})$ & Added $(\mu \mathrm{M})$ & Total found $(\mu \mathrm{M})$ & Recovery $(\mu \mathrm{M})$ & RSD (\%) \\
\hline 1 & 55.1 & 50 & 103.3 & 96.4 & 2.2 \\
\hline 2 & 54.7 & 100 & 158.3 & 103.6 & 2.8 \\
\hline
\end{tabular}

fluorescence quenching by amaranth was caused by IFE and NRET.

\section{Interference study}

To test specificity and selectivity of our developed nanosensor during amaranth analysis in real samples, C-dots fluorescence responses were analyzed under the presence of various potentially-interfering substances such as sugars (glucose, starch and malt sugar), vitamins (vitamin $C$ and vitamin $B_{1}$ ), amino acids (glycine, phenylalanine, tyrosine, threonine, alanine and glutamic acid) and salts ( $\mathrm{KCl}, \mathrm{CaCl}_{2}, \mathrm{ZnCl}_{2}, \mathrm{FeCl}_{3}$ and $\mathrm{NaCl}$ ). As shown by Fig. 5, C-dots fluorescence is significantly quenched by amaranth at the concentration of $5 \mu \mathrm{M}$. In contrast, presence of other interfering substances even at concentrations 20-60 times higher than amaranth concentration did not show any significant interference on the C-dots fluorescence. Thus, our as-synthesized C-dots can be used to construct highly selective nanosensor to detect amaranth in real samples.

\section{Detection of amaranth in drinks}

To further evaluate the practicability and accuracy of our C-dotsbased nanosensor, we tested it using grape juice drinks (the main ingredients: water, sugar, citric, vitamin C, sodium carboxymethyl cellulose, aspartame, acesulfame potassium, essence, grape juice and amaranth), which were purchased from a local store and used as received. Table 1 shows the analytical data and recovery values of three drink samples. The recovery values ranged from $96.4 \%$ to $103.6 \%$ and the RSD $(n=$ 3) was less than $2.8 \%$, which indicates that our developed nanosensor is very accurate and can be used for amaranth detection in consumer beverages.

\section{Conclusion}

We have successfully constructed and applied a new fluorescence nanosensor based on C-dots for the determination of amaranth. This sensor is based on fluorescence quenching of Cdots by amaranth. Specific quenching mechanism was related to the IFE and NRET. C-dots were synthesized using urea and glycine as precursors through a quick, inexpensive and environmentally friendly microwave-assisted method. Assynthesized C-dots display excellent solubility in water and strong fluorescence. The nanosensor constructed using C-dots as active material exhibited excellent selectivity and sensitivity towards amaranth. We obtained a good linear relationship between amaranth concentration and $F_{0} / F$ in the $0.2-30 \mu \mathrm{M}$ range. Detection limit of amaranth using this method was 0.021 $\mu \mathrm{M}$. Comparison with previous methods showed that our novel sensor has several advantages, which include its simplicity in design, fabrication and operation, low cost, rapid response, good selectivity and high sensitivity. Furthermore, the asconstructed nanosensor was successfully utilized for the detection of amaranth in consumer beverages. It indicates that the presented nanosensor is a promising sensing platform for amaranth detection.

\section{Conflicts of interest}

There are no conflicts to declare.

\section{Acknowledgements}

The authors gratefully thank the financial supports by the Doctoral Science Research Fund of Shanxi Datong University under grants No. 2014-B-13 and 2016-B-13, Industry Key Research and Development Plan Project Fund of Datong City under grant No. 2018014 as well as the National Nature Science Foundation of China under grant No. 21375083.

\section{Notes and references}

1 R. Sarıkaya, M. Selvi and F. Erkoç, Chemosphere, 2012, 8, 974979.

2 P. Mpountoukas, A. Pantazaki, E. Kostareli, P. Christodoulou, D. Kareli, S. Poliliou, C. Mourelatos, V. Lambropoulou and T. Lialiaris, Food Chem. Toxicol., 2010, 10, 2934-2944.

3 J. Zhang, M. L. Wang, C. S. Tu, W. C. Wang and Z. D. Chen, Food Chem., 2014, 160, 11-15.

4 K. S. Minioti, C. F. Sakellariou and N. S. Thomaidis, Anal. Chim. Acta, 2007, 583, 103-110.

5 G. Karanikolopoulos, A. Gerakis, K. Papadopoulou and I. Mastrantoni, Food Chem., 2015, 177, 197-203.

6 H. Wu, J. B. Guo, L. M. Du, H. Tian, C. X. Hao, Z. F. Wang and J. Y. Wang, Food Chem., 2013, 141, 182-186.

7 X. H. Chen, Y. G. Zhao, H. Y. Shen, L. X. Zhou, S. D. Pan and M. C. Jin, J. Chromatogr. A, 2014, 1346, 123-128.

$8 \mathrm{~J} . \mathrm{Ju}$ and L. P. Guo, Chin. J. Anal. Chem., 2013, 41, 681-686.

9 Y. D. Gao, L. Wang, Y. L. Zhang, L. N. Zou, G. P. Li and B. X. Ye, Talanta, 2017, 168, 146-151.

10 J. Zhang, M. L. Wang, C. Shentu, W. C. Wang and Z. D. Chen, Food Chem., 2014, 160, 11-15. 
11 M. Ryvolová, P. Táborský, P. Vrábel, P. Krásenský and J. Preisler, J. Chromatogr. A, 2007, 1141, 206-211.

12 F. I. Andrade, M. I. F. Guedes, Í. G. P. Vieira, F. N. P. Mendes, P. A. S. Rodrigues, C. S. C. Maia, M. M. M. Ávila and L. M. Ribeiro, Food Chem., 2014, 157, 193-198.

13 B. Zhang, D. L. Du, M. Meng, S. A. Eremin, V. B. Rybakov, J. H. Zhao, Y. M. Yin and R. M. Xi, Food Anal. Methods, 2014, 7, 1498-1505.

14 S. Qian, L. Qiao, W. Xu, K. Jiang, Y. Wang and H. Lin, Talanta, 2019, 194, 598-603.

15 C. Qu, D. Zhang, R. Yang, J. Hu and L. Qu, Spectrochim. Acta, Part A, 2019, 206, 588-596.

16 S. Y. Lim, W. Shen and Z. Q. Gao, Chem. Soc. Rev., 2015, 44, 362-381.

17 S. Mondal, R. Thirupathi and H. S. Atreya, $R S C A d v ., 2015,5$, 4489-4492.

18 X. Y. Xu, R. Ray, Y. L. Gu, H. J. Ploehn, L. Gearheart, K. Raker and W. A. Scrivens, J. Am. Chem. Soc., 2004, 126, 1273612737.

19 F. Wang, S. Pang, L. Wang, Q. Li, M. Kreiter and C.-Y. Liu, Chem. Mater., 2010, 22, 4528-4530.

20 H. Goncalves, P. A. S. Jorge and J. R. A. Fernandes, Sens. Actuators, B, 2010, 145, 702-707.

21 Y. Li, Y. Hu, Y. Zhao, G. Shi, L. Deng, Y. Hou and L. Qu, Adv. Mater., 2011, 23, 776-780.

22 X. Xu, R. Ray, Y. Gu, H. J. Ploehn, L. Gearheart, K. Raker and W. A. Scrivens, J. Am. Chem. Soc., 2004, 126, 12736-12737.

23 L. Tang, R. Ji, X. Cao, J. Lin, H. Jiang, X. Li, K. S. Teng, C. M. Luk, S. Zeng and J. Hao, ACS Nano, 2012, 6, 5102-5110.

24 Y. Chen, Y. Wu, B. Weng, B. Wang and C. Li, Sens. Actuators, $B, 2016,223,689-696$.

25 X. Wang, K. Qu, B. Xu, J. Ren and X. Qu, J. Mater. Chem., 2011, 21, 2445-2450.

26 H. Zhu, X. L. Wang, Y. L. Li, Z. J. Wang, F. Yang and X. R. Yang, Chem. Commun., 2009, 34, 5118-5120.

27 S. Y. Lim, W. Shen and Z. Gao, Chem. Soc. Rev., 2015, 44, 362381.

28 F. Lu, Y. Song, H. Huang, Y. Liu, Y. Fu, J. Huang, H. Li, H. Qu and Z. Kang, Carbon, 2017, 120, 95-102.

29 Q. Xu, T. Kuang, Y. Liu, L. Cai, X. Peng, T. S. Sreeprasad, P. Zhao, Z. Yu and N. Li, J. Mater. Chem. B, 2016, 4, 72047219.

30 J. Bhamore, S. Jha, T. J. Park and S. K. Kailasa, Sens. Actuators, B, 2018, 277, 47-54.

31 S. K. Kailasa, S. Ha, S. H. Baek, L. M. T. Phan, S. Kim, K. Kwak and T. J. Park, Mater. Sci. Eng., C, 2019, 98, 834-842.

32 V. Mehta, S. Jha and S. K. Kailasa, Mater. Sci. Eng., C, 2014, 38, 20-27.

33 Z. Ma, Y.-L. Zhang, L. Wang, H. Ming, H. Li, X. Zhang, F. Wang, Y. Liu, Z. Kang and S.-T. Lee, ACS Appl. Mater. Interfaces, 2013, 5, 5080-5084.
34 T. Feng, X. Ai, G. An, P. Yang and Y. Zhao, ACS Nano, 2016, 10, 4410-4420.

35 E. G. Ju, Z. Liu, Y. D. Du, Y. Tao, J. S. Ren and X. G. Qu, ACS Nano, 2014, 8, 6014-6023.

36 S. Sooksin, V. Promarak, S. Ittisanronnachai and W. Ngeontae, Sens. Actuators, B, 2018, 262, 720-732.

37 Y. Zhang, X. Fang, H. Zhao and Z. Li, A highly sensitive and selective detection of $\mathrm{Cr}(\mathrm{VI})$ and ascorbic acid based on nitrogen-doped carbon dots, Talanta, 2018, 181, 318-325.

38 M. Zan, L. Rao, H. Huang, W. Xie, D. Zhu, L. Li, X. Qie, S.-S. Guo, X.-Z. Zhao, W. Liu and W.-F. Dong, Sens. Actuators, B, 2018, 262, 555-561.

39 D. K. Dang, S. Chandrasekaran, Y.-L. T. Ngo, J. S. Chung, E. J. Kim and S. H. Hur, Sens. Actuators, B, 2018, 255, 3284-3291.

40 H. Zeng, L. Li, Y. Ding and Q. Zhuang, Talanta, 2018, 178, 879-885.

41 L. Lin, M. Rong, S. Lu, X. Song, Y. Zhong, J. Yan, Y. Wang and X. Chen, Nanoscale, 2015, 7, 1872-1878.

42 L. Lin and S. Zhang, Chem. Commun., 2012, 48, 10177-10179. 43 C. Hu, Y. Liu, Y. Yang, J. Cui, Z. Huang, Y. Wang, L. Yang, H. Wang, Y. Xiao and J. Rong, J. Mater. Chem., 2013, 1, 39-42.

44 Y. Dong, H. Pang, H. B. Yang, C. Guo, J. Shao, Y. Chi, C. M. Li and T. Yu, Angew. Chem., Int. Ed., 2013, 125, 7954-7958.

45 S. J. Zhu, Q. N. Meng, L. Wang, J. H. Zhang, Y. B. Song, H. Jin, K. Zhang, H. C. Sun, H. Y. Wang and B. Yang, Angew. Chem., Int. Ed., 2013, 52, 3953-3957.

46 Q. Hu, M. C. Paau, Y. Zhang, X. Gong, L. Zheng, D. Lu, Y. Liu, Q. Liu, J. Yao and M. M. F. Choi, RSC Adv., 2014, 4, 1806518073.

47 Q. Xu, Y. Liu, C. Gao, J. Wei, H. Zhou, Y. Chen, C. Dong, T. S. Sreeprasad, N. Li and Z. Xia, J. Mater. Chem. C, 2015, 3, 9885-9893.

48 S. Chandra, P. Patra, S. H. Pathan, S. Roy, S. Mitra, A. Layek, R. Bhar, P. Pramanik and A. Goswami, J. Mater. Chem. B, 2013, 1, 2375-2382.

49 Y. Liu, Q. Zhou, Y. Yuan and Y. Wu, Carbon, 2017, 115, 550560.

50 F. Yan, D. Kong, Y. Luo, Q. Ye, J. He, X. Guo and L. Chen, Microchim. Acta, 2016, 183, 1611-1618.

51 W. P. Hu, G. D. Cao, W. Dong, H. B. Shen, X. H. Liu and L. S. Li, Anal. Methods, 2014, 6, 1442-1447.

52 S. P. Alves, D. M. Brum, É. C. B. Andrade and A. D. P. Netto, Food Chem., 2008, 107, 489-496.

53 H. Liu, C. Xu, Y. Bai, L. Liu, D. Liao, J. Liang, L. Liu and H. Han, Spectrochim. Acta, Part A, 2017, 171, 311-316.

54 Y. Z. Fan, Y. Zhang, N. Li, S. G. Liu, T. Liu, N. B. Li and H. Q. Luo, Sens. Actuators, B, 2017, 240, 949-955.

55 Z. Zhang, Y. Liu, Z. Yan and J. Chen, Sens. Actuators, B, 2018, 255, 986-994.

56 G. H. G. Ahmed, R. B. Laíño, J. A. G. Calzón and M. E. D. García, Talanta, 2015, 132, 252-257. 